Check for updates

Cite this: RSC Adv., 2018, 8, 31055

\title{
Copper antimony sulfide thin films for visible to near infrared photodetector applications $\uparrow$
}

\author{
V. Vinayakumar, (D) a S. Shaji, (D) ab D. Avellaneda, ${ }^{a}$ J. A. Aguilar-Martínez (D) ac \\ and B. Krishnan (D)*ab
}

Ternary chalcostibite copper antimony sulfide $\left(\mathrm{CuSbS}_{2}\right)$ is an emerging semiconductor material having applications in photovoltaics, energy storage and optoelectronics due to its high absorption coefficient, suitable bandgap, and it consists of non-toxic and earth abundant elements. $\mathrm{CuSbS}_{2}$ thin films are prepared by combining chemical bath deposition (antimony sulfide $\left(\mathrm{Sb}_{2} \mathrm{~S}_{3}\right)$ ) and thermal evaporation (copper $(\mathrm{Cu})$ ) followed by a heat treatment and their application as visible to near infrared photodetectors is reported. Crystalline structure, elemental composition, chemical state, morphology and optoelectronic properties of the films were characterized by various techniques. The effect of three different $\mathrm{Cu}$ thicknesses (CAS 20, CAS 30 and CAS $40 \mathrm{~nm}$ ) on the photodetection properties are evaluated under illumination using light emitting diodes (LEDs) and a laser. The photodetectors fabricated are successfully tested under different wavelengths, power densities and applied voltage and their photoresponse cyclic stability for each wavelength of illumination was recorded. From the sensitivity calculations, the sample with $20 \mathrm{~nm}$ Cu thickness (CAS 20) showed higher detection sensitivity for visible to near infrared wavelengths. Better responsivity results were obtained for CAS 40 because of its improved crystallinity and phase purity. Photodetector properties such as sensitivity and responsivity are evaluated for all the samples. These results are beneficial for cost effective and environment friendly photodetectors and optoelectronic devices based on $\mathrm{CuSbS}_{2}$ thin films.

Received 2nd July 2018

Accepted 22nd August 2018

DOI: $10.1039 / \mathrm{c} 8 \mathrm{ra05662e}$

rsc.li/rsc-advances sensitivity and stability. ${ }^{3}$ A flexible photodetector was fabricated using aluminum doped zinc oxide (Al:ZnO) and CIGS nanorods where the improved photocurrent was attributed to the light trapping properties and core shell structure of CIGS. ${ }^{4}$ However, indium (In) in these chalcogenide materials is expensive due to its scarcity. Antimony (Sb) is the best substitute for In due to its similar chemistry, thus forming $\mathrm{CuSbS}_{2}{ }^{5,6}$

Copper antimony sulfide ( $\mathrm{CuSbS}_{2}$ or CAS) is a newly emerging p-type semiconductor, which has attracted much attention due to its versatile properties, environmentally benign and earth abundant precursor materials and cost consideration. ${ }^{5,7-10}$ So far, the focus of researchers has been in exploring the photovoltaic properties of $\mathrm{CuSbS}_{2}$ as an absorbing layer due to its appropriate bandgap of $1.5 \mathrm{eV}^{11,12}$ (optimum for photovoltaic solar energy conversion), a high absorption coefficient $\sim 10^{5} \mathrm{~cm}^{-1},{ }^{12-15}$ tunable hole concentration in a range of $10^{16}-10^{18} \mathrm{~cm}^{-1},{ }^{16,17}$ hole mobility of $49 \mathrm{~cm}^{2}(\mathrm{~V} \mathrm{~s})^{-1}$, grain growth at relatively low temperatures and the Spectroscopic Limited Maximum Efficiency (SLME) of $22.9 \% .^{13,18,19}$ Additionally, interesting optoelectronic properties, especially in the visible-near infrared (NIR) region, for $\mathrm{CuSbS}_{2}$ can make it an inventive candidate in optoelectronic devices. Hao et al. reported the synthesis of $\mathrm{CuSbS}_{2}$ nanocrystals using a hot injection method and fabrication of a high performance hybrid photodetector based on a poly(3hexylthiophene):CuSbS 2 hybrid films ${ }^{6}$ where, the $\mathrm{CuSbS}_{2}$ acted as San Nicolás de los Garza, Nuevo León, 66455, Mexico. E-mail: krishnan.bindu@ Universidad Autónoma de Nuevo León, Parque de Investigación e Innovación Tecnológica, Apodaca, Nuevo León 66600, Mexico

${ }^{c}$ Centro de Investigación e Innovación en Ingeniería Aeronáutica (CIIIA), Facultad de Ingeniería Mecánica y Eléctrica, Carretera a Salinas Victoria, km. 2.3, C.P. 66600 Apodaca, Nuevo León, Mexico

$\dagger$ Electronic supplementary information (ESI) available. See DOI: 10.1039/c8ra05662e 
a photoelectron accepter due to its high electron affinity. Application of $\mathrm{CuSbS}_{2}$ as an anode material in charge storage devices was also explored by the research community. ${ }^{\mathbf{2 0}-22}$

Thin films of $\mathrm{CuSbS}_{2}$ have been fabricated using various chemical and physical methods such as chemical bath deposition, ${ }^{23}$ spray pyrolysis, ${ }^{24}$ spin coating, ${ }^{9}$ electro deposition, ${ }^{25}$ thermal evaporation ${ }^{26}$ and co-sputtering. ${ }^{5}$ Chemical bath deposition (CBD) is a relatively less expensive thin film fabrication technique due to the absence of sophisticated instrumentation and vacuum system. Use of non-conductive substrates, large area and uniform deposition are other advantages of CBD. ${ }^{27,28}$ Thermal evaporation on the other hand acquires uniform thin films by heating the target material and condensing on the substrate. Pre-defined thin film thickness with accuracy in the nanometer range is one of the major advantages of thermal evaporation technique. Garza et al. fabricated $\mathrm{CuSbS}_{2}$ thin films by combined chemical bath and thermal evaporation techniques followed by a heat treatment. ${ }^{8}$ Furthermore, we have reported the successful fabrication of single phase $\mathrm{CuSbS}_{2}$ thin films by a rapid thermal processing (RTP) applied to glass $/ \mathrm{Sb}_{2} \mathrm{~S}_{3} / \mathrm{Cu}$ stacked layer pre-annealed in a vacuum system. ${ }^{29}$

In this work, we report the fabrication of $\mathrm{CuSbS}_{2}$ thin films on glass substrates for photodetection application. Thin films of $\mathrm{Sb}_{2} \mathrm{~S}_{3}$ and $\mathrm{Cu}$ (thicknesses of 20,30 and $40 \mathrm{~nm}$ ) were deposited on glass substrates by chemical bath deposition followed by thermal evaporation technique. $\mathrm{CuSbS}_{2}$ thin films were obtained by a heat treatment in vacuum oven for $\mathrm{Sb}_{2} \mathrm{~S}_{3} / \mathrm{Cu}$ precursors at $380{ }^{\circ} \mathrm{C}$. CAS thin films synthesized were characterized using various techniques such as X-ray diffraction (XRD), Raman spectroscopy, Xray photoelectron spectroscopy (XPS), scanning electron microscopy (SEM), atomic force microscopy (AFM), UV-Vis NIR spectroscopy and an electrical measurement system. Photodetector properties were investigated using LED lights of different wavelength illuminations, applied voltages and laser power densities. The photodetector with 40 and $30 \mathrm{~nm} \mathrm{Cu}$ thickness showed better photodetector characteristics in the visible region where as the one with $20 \mathrm{~nm}$ showed better NIR response. The details of the characterization of CAS thin films and their photodetector properties are described. The results show that the CAS thin films are of good visible to NIR light response at low applied voltages (1, 3 and $5 \mathrm{~V}$ ), linear photocurrent response with stable and reproducible photodetection properties.

\section{Experimental procedure}

\subsection{Materials}

Neutral soap solution, isopropyl alcohol, antimony trichloride $\left(\mathrm{SbCl}_{3}-99.999 \%\right)$ powder, sodium thiosulfate pentahydrate $\left(\mathrm{Na}_{2} \mathrm{~S}_{2} \mathrm{O}_{3} \cdot 5 \mathrm{H}_{2} 0-99.999 \%\right)$ powder and acetone were supplied by Fermont. All the chemicals were used as received. Copper wire (Cu-99.999\%) was purchased from Alpha Aesar.

\subsection{Preparation of $\mathrm{CuSbS}_{2}$ thin film}

Chemical bath deposition (CBD) technique was employed to deposit thin films of antimony sulfide $\left(\mathrm{Sb}_{2} \mathrm{~S}_{3}\right)$ on glass substrates $^{30}$ from a bath containing $650 \mathrm{mg}$ of antimony trichloride $\left(\mathrm{SbCl}_{3}\right)$ dissolved in $2.5 \mathrm{ml}$ of acetone, $25 \mathrm{ml}$ of sodium thiosulfate pentahydrate $\left(\mathrm{Na}_{2} \mathrm{~S}_{2} \mathrm{O}_{3} \cdot 5 \mathrm{H}_{2} \mathrm{O}\right)$ having concentration of $1 \mathrm{M}$ and $72.5 \mathrm{ml}$ of deionized water $\left(25^{\circ} \mathrm{C}\right) \cdot{ }^{29}$ The whole mixture was stirred well and poured slowly into Petri dish without making bubbles where the well cleaned glass substrates (ultrasonically cleaned with isopropanol, neutral soap solution and distilled water) were placed horizontally. The deposition was carried out at $25{ }^{\circ} \mathrm{C}$ for 2 hours. Afterwards, the substrates with thin films were removed from the Petri dish and rinsed with distilled water and dried using hot air. As prepared $\mathrm{Sb}_{2} \mathrm{~S}_{3}$ films were orange-yellow in color and uniformly reflective.

Copper layers of thicknesses 20, 30 and $40 \mathrm{~nm}$ were deposited on $\mathrm{Sb}_{2} \mathrm{~S}_{3}$ thin films coated glass substrates by thermal evaporation of copper in a high vacuum system (Torr International, Model No: THE2-2.5KW-TP) at a pressure of $10^{-6}$ torr with a rate of $1 \AA^{-1}$ and substrate rotation of $20 \mathrm{rpm} .99 .999 \%$ pure copper wire was used as the evaporation material. Thickness of the $\mathrm{Cu}$ film was measured in situ using a quartz crystal thickness monitor installed in the evaporation system. Copper antimony sulfide $\left(\mathrm{CuSbS}_{2}\right.$ (CAS)) phase was formed by annealing glass $/ \mathrm{Sb}_{2} \mathrm{~S}_{3} / \mathrm{Cu}$ precursor layers with different $\mathrm{Cu}$ thicknesses in a vacuum oven $\left(10^{-3}\right.$ torr) at $380{ }^{\circ} \mathrm{C}$ for 1 hour. Samples annealed were labelled as CAS 20, CAS 30 and CAS 40 depending on the thickness of the Cu layer (in $\mathrm{nm}$ ) deposited on $\mathrm{Sb}_{2} \mathrm{~S}_{3}$ thin films.

\subsection{Characterization}

The structural properties of $\mathrm{CuSbS}_{2}$ thin films were characterized by X-ray diffraction technique (PANalytical Empyrean Diffractometer which employs $\mathrm{Cu} \mathrm{K} \alpha 1$ radiation $(\lambda=1.54056 \AA)$ ) in the range of $2 \theta=10-60^{\circ}$. Raman spectroscopy (Thermo Scientific DXR Raman Microscope) was used to identify the phases present in these CAS thin films. The elemental composition and chemical states were analysed by X-ray photoelectron spectroscopy (XPS, Thermo Scientific K-Alpha) with a monochromatized Al K $\alpha$ radiation $(h \nu=1486.88 \mathrm{eV})$. Scanning electron microscopy (SEM, Hitachi Model SU 8020) and atomic force microscopy (AFM, NT-MDT Model Solver Pro) were used to characterize the morphology as well as surface roughness of the films. Optical spectral measurements were carried out using an ultraviolet-visible-near infrared spectrophotometer (Jasco V770). Transmittance as well as absorbance measurements were done by keeping a bare glass substrate as reference in the wavelength range of 400 to $1000 \mathrm{~nm}$. The optical energy bandgap $\left(E_{\mathrm{g}}\right)$ values were evaluated using Tauc plot between $(\alpha h \nu)^{2} v s$. $h \nu$ for all the films. Electrical properties as well as photoresponse measurements were carried out under the illumination from light emitting diodes (LEDs) having wavelengths of 450, 620, 740 and $850 \mathrm{~nm}$ and optical power of $20 \mathrm{~W}$ using a picoammeter/voltage source meter (Keithley 6487). A pair of silver electrodes of $5 \mathrm{~mm}$ in length separated by $5 \mathrm{~mm}$ were painted using conductive silver paint (SPI ${ }^{\circledR}$ supplies) and dried on the sample surface for the photodetector characterization. The current voltage measurements were carried out under dark as well as illumination for applied voltages from -5 to $+5 \mathrm{~V}$. Photoresponse switching behaviour of the $\mathrm{CuSbS}_{2}$ thin films 
were measured at different applied potentials of 1,3 and $5 \mathrm{~V}$ where the LED illumination was turned on and off at each $5^{\text {th }}$ and $10^{\text {th }}$ seconds respectively.

Photodetection properties of CAS thin films for various intensities were measured by illuminating the samples using a diode pumped continuous wave laser of $532 \mathrm{~nm}$ with adjustable output power. The laser spot was expanded using a concave lens and the sample area excess of the electrode dimension was masked to avoid illumination. The same voltage source (Keithley 6487) used to apply voltage and simultaneously to measure current while the samples were illuminated by the laser. Laser output power was varied from $2 \mathrm{~mW}$ to $40 \mathrm{~mW}(2,6$, $10,20,30$, and $40 \mathrm{mWs}$ ) during constant bias voltages 1,3 and $5 \mathrm{~V}$ and photoresponse was measured for $20 \mathrm{~s}$ in dark, $20 \mathrm{~s}$ in light followed by another $20 \mathrm{~s}$ in dark.

\section{Results and discussion}

\subsection{Structural analysis}

$\mathrm{X}$-ray diffraction at grazing incidence mode was carried out for these CAS thin films for their structural characterization. Copper thicknesses of 20,30 and $40 \mathrm{~nm}$ were selected to optimize the photoconductive properties of the CAS thin films. Structural characterization of CAS 20, CAS 30 and CAS 40 thin films annealed at $380{ }^{\circ} \mathrm{C}$ for $1 \mathrm{~h}$ is shown in Fig. 1. The diffraction patterns were collected at $0.5^{\circ}$ incident angle in grazing incident mode for all the samples. The major reflections observed in XRD are from the planes (200), (101), (111), (410), (301), (501), (221), (321), (002), (800), and (212) that correspond to the orthorhombic crystal structure of $\mathrm{CuSbS}_{2}$ (JCPD\#441417). These XRD peaks are matching well with the reported results., ${ }^{\mathbf{9 1 1}, 31,32}$ Nair et al. reported the formation of ternary $\mathrm{CuSbS}_{2}$ films by annealing chemically deposited multilayer thin films $\mathrm{s}^{7,31}$ and Yang et al. by spin coating followed by a hot plate heat treatment. ${ }^{9}$ In both studies, the major XRD reflections are from the same planes as we observed in the present work. Phase pure $\mathrm{CuSbS}_{2}$ peaks with improved crystalline nature was observed for the CAS $40 \mathrm{~nm}$ film from the diffraction pattern analysis. The intensity of the peak corresponds to the plane (111) is diminished whereas more orientations are noted along (410), (301), (501) and (212) planes. JCPDS reference data for orthorhombic $\mathrm{CuSbS}_{2}$ is also provided in Fig. 1. All the peaks in the reference JCPDS are identified in the CAS 40 thin film. For CAS 20 and CAS 30 films, reflections from the planes (020) and (120) correspond to $\mathrm{Sb}_{2} \mathrm{~S}_{3}$ for the stibnite crystal structure (JCPDS\#42-1393). This could be attributed to the deficiency of $\mathrm{Cu}$ in the CAS 20 and CAS 30 thin films to form the complete ternary CAS phase. A feeble amount of $\mathrm{Cu}_{2} \mathrm{~S}$ impurity is also identified at $2 \theta$ value 13.8 in these samples irrespective of the $\mathrm{Cu}$ thicknesses (chalcostibite, JCPDS\#83-1462). The presence of impurity $\mathrm{Cu}_{2} \mathrm{~S}$ peak at the same $2 \theta$ value was reported by Aquino et $a .^{33}$ and Acosta et al. ${ }^{11}$ where, the films were prepared by spray pyrolysis and combined chemical bath and thermal evaporation techniques. Colombara et al. reported the sulfurization of $\mathrm{Sb}-\mathrm{Cu}$ metal precursors at different temperatures which resulted in the formation of $\mathrm{CuSbS}_{2}$ films with a minor presence of binary CuS phase. ${ }^{34}$ These studies report the binary

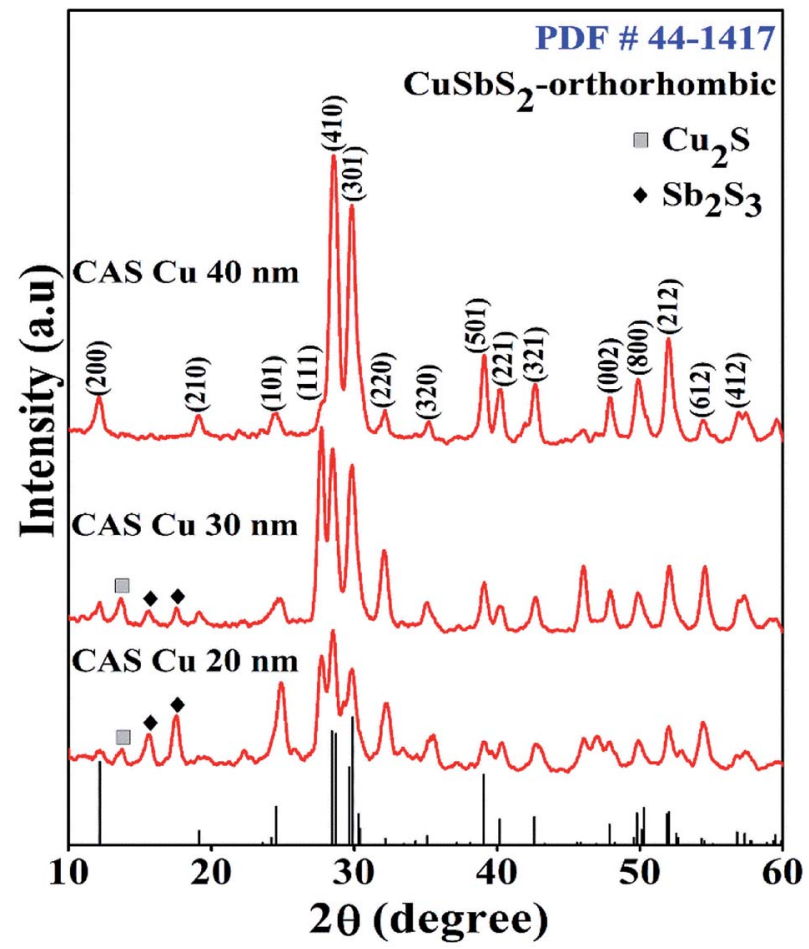

Fig. 1 XRD pattern of $\mathrm{CuSbS}_{2}$ thin films with varying $\mathrm{Cu}$ thicknesses 20, 30 and $40 \mathrm{~nm}$ annealed at $380{ }^{\circ} \mathrm{C}$ for $1 \mathrm{~h}$ in vacuum oven. The standard pattern corresponding to orthorhombic $\mathrm{CuSbS}_{2}$ is included (PDF\#44-1417).

impurity phases ( $\mathrm{CuS}$ and $\mathrm{Cu}_{2} \mathrm{~S}$ ) formation during the synthesis of ternary $\mathrm{CuSbS}_{2}$ phase. However, as the $\mathrm{Cu}$ thickness increased from 20 to $30 \mathrm{~nm}$, the intensity of peaks corresponding to $\mathrm{CuSbS}_{2}$ also increased significantly while diminishing the $\mathrm{Sb}_{2} \mathrm{~S}_{3}$ peak intensities. The average crystallite sizes of all the CAS films with different $\mathrm{Cu}$ thicknesses were evaluated using Scherrer equation, ${ }^{29,35}$

$$
D=\frac{0.9 \lambda}{\beta \cos \theta}
$$

where, $\lambda$ is the wavelength of the $\mathrm{X}$-ray radiation (1.54056 $\AA$ ), $\theta$ is the Bragg angle and $\beta$ is the full width at the half maximum (FWHM) of the (410) peak. The crystalline size estimated from the Scherrer equation are 13, 13.6 and $14.6 \mathrm{~nm}$ for the CAS 20, CAS 30 and CAS 40 samples respectively where the crystalline size increased with the increase in the $\mathrm{Cu}$ layer thickness. All these results are comparable with previously reported results. ${ }^{29}$

\subsection{Raman analysis}

Fig. 2 shows the Raman spectra using $532 \mathrm{~nm}$ laser excitation for identification of crystalline phases present in the films. As specified by Baker et al., ${ }^{36} \mathrm{CuSbS}_{2}$ possess four Raman active modes represented by $\mathrm{Ag}, \mathrm{B} 1 \mathrm{~g}, \mathrm{~B} 2 \mathrm{~g}$ and $\mathrm{B} 3 \mathrm{~g}$ and three infrared active modes $\mathrm{B} 1 \mathrm{u}, \mathrm{B} 2 \mathrm{u}$ and $\mathrm{B} 3 \mathrm{u}$. The present spectra shows Raman bands at 98, 112, 150, 274, 303 and $333 \mathrm{~cm}^{-1}$ where the peaks at 98,112, 150 and $333 \mathrm{~cm}^{-1}$ are attributed to the vibrational modes of $\mathrm{CAS}^{33,36-39}$ and the peaks at 274 and $303 \mathrm{~cm}^{-1}$ 


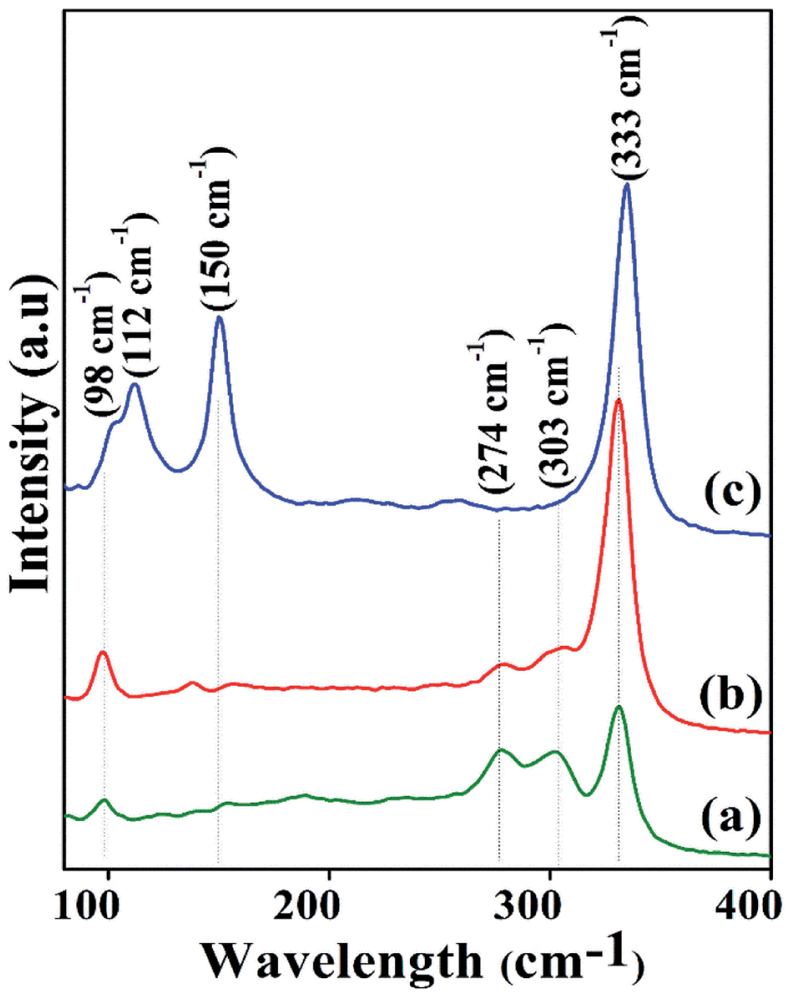

Fig. 2 Raman spectra of CAS thin films with varying Cu thicknesses (a) 20, (b) 30 and (c) $40 \mathrm{~nm}$ annealed at $380^{\circ} \mathrm{C}$ for 1 hour in vacuum oven.
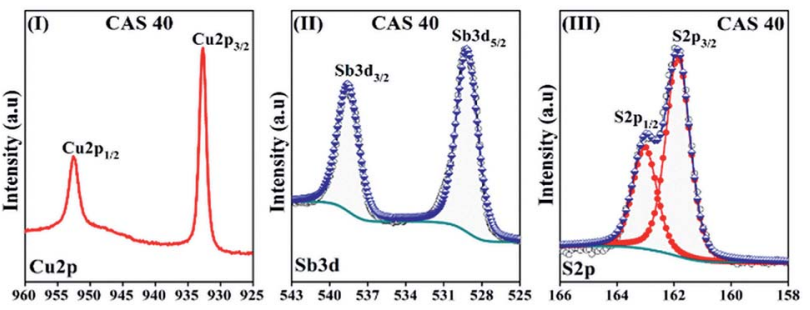

Binding energy $(\mathrm{eV})$
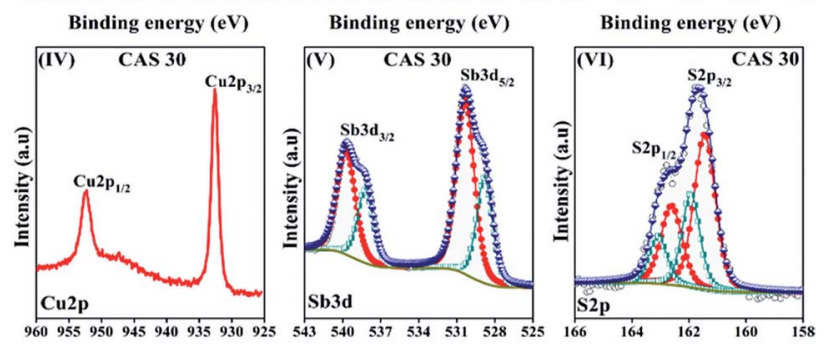

Binding energy $(\mathrm{eV})$
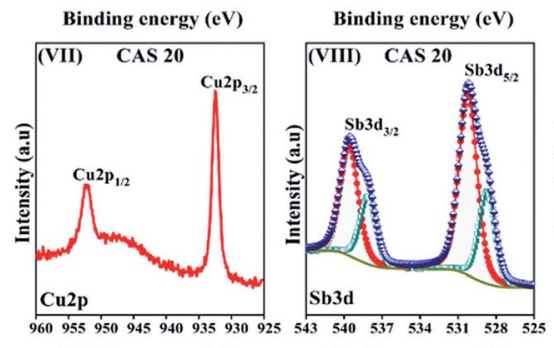

Binding energy (eV)

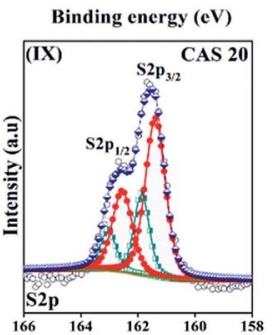

Binding energy $(\mathrm{eV})$

Fig. 3 High resolution spectra of Cu2p, Sb3d and S2p of CAS 40 (I-III), CAS $30(\mathrm{IV}-\mathrm{V})$ and CAS $20(\mathrm{VI}-\mathrm{IX})$ thin films.

correspond to the $\mathrm{Sb}_{2} \mathrm{~S}_{3}$ phase. ${ }^{40,41}$ Raman peak values obtained for the samples are in good agreement with the reported Raman active vibrations of CAS and $\mathrm{Sb}_{2} \mathrm{~S}_{3}$. Raman intensity of the CAS peak at $333 \mathrm{~cm}^{-1}$ is increased significantly as $\mathrm{Cu}$ thickness raised from 20 to $40 \mathrm{~nm}$ which is in good agreement with the $\mathrm{XRD}$ results. As seen in the figure, presence of precursor $\mathrm{Sb}_{2} \mathrm{~S}_{3}$ is noted in the CAS films with $\mathrm{Cu}$ thickness $20 \mathrm{~nm}$ and minor traces in $30 \mathrm{~nm}$. However, the intensities of the peaks corresponding to $\mathrm{Sb}_{2} \mathrm{~S}_{3}\left(274\right.$ and $303 \mathrm{~cm}^{-1}$ ) are decreasing gradually with increase in $\mathrm{Cu}$ thickness. It can be inferred from the Raman spectra that both these films contain CAS as the major phase along with small contribution from the unreacted $\mathrm{Sb}_{2} \mathrm{~S}_{3}$ phase. CAS $40 \mathrm{~nm}$ film shows two additional peaks at 112 and $150 \mathrm{~cm}^{-1}$ along with the major peak at $333 \mathrm{~cm}^{-1}$ which also corresponds to the $\mathrm{CuSbS}_{2}$ phase. These peaks are also identical with the RRUFF project data base of the Raman spectra of $\mathrm{CuSbS}_{2}$ sample at $532 \mathrm{~nm}$ excitation wavelength ${ }^{42}$ as well as with our previous reports. ${ }^{29,33}$ Raman results indicate the phase purity for $\mathrm{CuSbS}_{2}$ thin films formed for $40 \mathrm{~nm} \mathrm{Cu}$ thickness (CAS 40). Results of the Raman spectra for CAS samples are in accordance with the XRD results obtained.

\subsection{X-ray photoelectron spectroscopy (XPS)}

$\mathrm{X}$-ray photoelectron spectroscopy was employed to determine the elemental composition and chemical states using a typical survey and high resolution spectral analyses of the CAS thin films. Low resolution survey spectra recorded from 0 to $1400 \mathrm{eV}$ were used for the elemental analysis of each sample (provided in ESI, Fig. S1 $\dagger$ ) whereas high resolution spectra of $\mathrm{Cu}, \mathrm{Sb}$ and $\mathrm{S}$ were used for the chemical states analysis. Fig. 3 shows the high-resolution photoelectron spectra of $\mathrm{Cu}, \mathrm{Sb}$ and $\mathrm{S}$ of $\mathrm{CAS} 20$, 30 and 40 from the first etch level where etching cycles were performed at a rate of $1.19 \mathrm{~nm} \mathrm{~s}^{-1}$ using $2 \mathrm{keV} \mathrm{Ar}^{+}$ions to remove the surface contaminants. A Shirley type background and a Gaussian-Lorentzian sum function were applied to the XPS high resolution spectra for deconvolution of the peaks, as shown in the figure. Fig. 3(I-III) presents the high-resolution scans of Cu2p, Sb3d and S2p core level spectra of CAS 40 thin film where, copper core level spectrum shows a $2 p$ doublet at the binding energies (B.E) $932.6 \mathrm{eV}$ and $952.3 \mathrm{eV}$ with a separation of $19.7 \mathrm{eV}$, which is consistent with previous reports for $\mathrm{Cu}^{2+}$ in $\mathrm{CuSbS}_{2}$. XPS analysis of $\mathrm{CuSbS}_{2}$ thin films by solution processing and spin coating were reported by Yang et al. and McCarthy et al. observed the similar B.E for Cu2p peaks. ${ }^{9,37}$ The $3 \mathrm{~d}$ core level spectra of antimony observed at $530.43 \mathrm{eV}\left(3 \mathrm{~d}_{5 / 2}\right)$ and $539.82 \mathrm{eV}\left(3 \mathrm{~d}_{3 / 2}\right)$ with a separation of $9.39 \mathrm{eV}$ match with $\mathrm{CuSbS}_{2}$ phase as reported earlier. ${ }^{29}$ The high-resolution core level spectra of S2p doublet is shown in Fig. 3(III). Deconvoluted high intensity peaks located at $161.7\left(2 \mathrm{p}_{3 / 2}\right)$ and $162.9\left(2 \mathrm{p}_{5 / 2}\right) \mathrm{eV}$ coincide with the reported B.E values of $\mathrm{CuSbS}_{2}$.

Fig. 3(IV-VI) and (VII-IX) represent the high-resolution spectra of CAS 30 and CAS 20 thin films respectively. They both present similar binding energy peaks as CAS $40 \mathrm{~nm}$ with an extra peak in S2p and Sb3d core levels. The smallest peak observed in S2p and Sb3d at $161.8 \mathrm{eV}\left(\mathrm{S} 2 \mathrm{p}_{3 / 2}\right), 163 \mathrm{eV}\left(\mathrm{S} 2 \mathrm{p}_{1 / 2}\right)$ with a separation of $1.2 \mathrm{eV}$ and $528.8 \mathrm{eV}\left(\mathrm{Sb} \mathrm{d}_{5 / 2}\right), 538.19 \mathrm{eV}$ the 

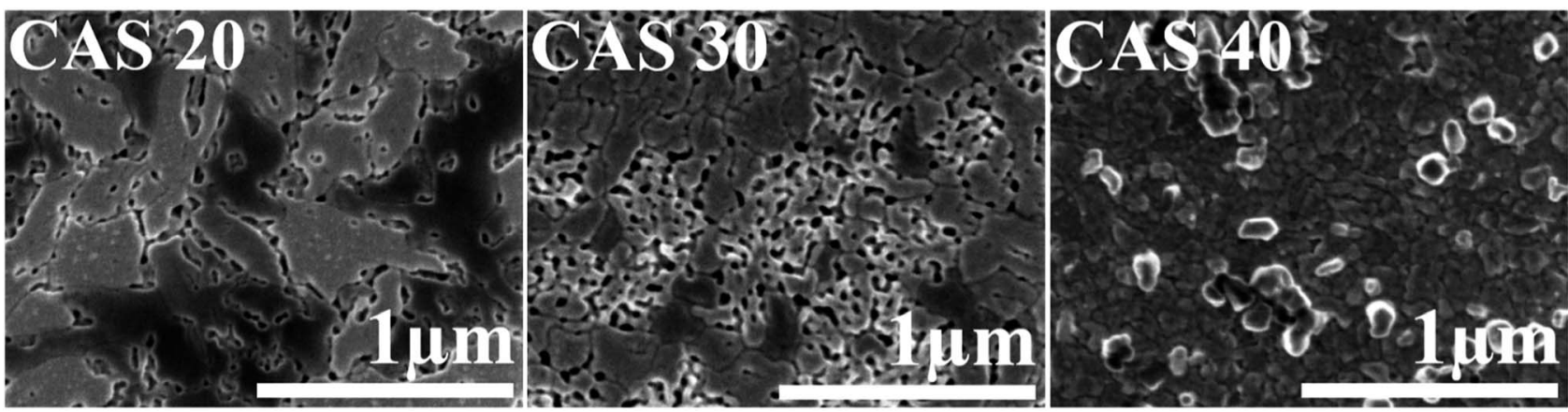

Fig. 4 Scanning electron micrographs for $\mathrm{CuSbS}_{2}$ thin films with 20 (CAS 20), 30 (CAS 30) and $40 \mathrm{~nm}$ (CAS 40) Cu thicknesses.

$\mathrm{Sb}_{2} \mathrm{~S}_{3}$ phase is highly intense in the CAS 30 and CAS 20 samples due to the presence of unreacted $\mathrm{Sb}_{2} \mathrm{~S}_{3}$ owing to the insufficient $\mathrm{Cu}$ thickness for complete CAS formation. The uniformity of $\mathrm{Cu}$, $\mathrm{Sb}$ and $\mathrm{S}$ elements throughout the depth of the films were observed in the depth profile analysis of each sample, one of them is included in the ESI (Fig. S2 $\dagger$ ). All these XPS results agree with that of XRD and Raman analysis.

\subsection{Morphological studies}

The morphology and surface roughness of the CAS thin films were analysed using SEM and AFM. Field emission scanning electron microscopic (FESEM) images of the annealed CAS thin films with varying $\mathrm{Cu}$ thicknesses are in Fig. 4. Images were collected in secondary electron imaging mode by applying $1 \mathrm{kV}$ at the same magnification $(50000 \times)$. All films show changes in as $\mathrm{Cu}$ thickness increases from 20 to $40 \mathrm{~nm}$. The CAS 20 film exhibits irregular shaped particles interconnected as seen in the figure. In the CAS 30 film, a compact morphology with better grains is observed. Pinhole free films with bigger grains with definite boundaries are formed when $\mathrm{Cu}$ thickness is increased to $40 \mathrm{~nm}$. These morphological analyses are consistent with our previous reports. ${ }^{\mathbf{8 1 1}, 29}$ The thickness of the films was measured by cross-sectional SEM analysis (images are provided in the ESI, Fig. S3 $\dagger$ ). The EDX spectrum taken from the samples reveals the peaks of $\mathrm{Cu}, \mathrm{Sb}$ and $\mathrm{S}$ as well as EDX mapping provide the information about the spatial distribution of different compositional elements of $\mathrm{CuSbS}_{2}$ (Fig. S4 and $55 \dagger$ ).

The surface morphology and roughness of all CAS films were investigated by atomic force microscopy (AFM) in contact mode. Fig. 5 $(\mathrm{a}-\mathrm{c})$ and $(\mathrm{d}-\mathrm{f})$ show the $2 \mathrm{D}$ as well as 3D AFM images of CAS thin films CAS 20, CAS 30 and CAS 40 respectively. From the figure, grain size and roughness of the films are increasing gradually with the increase in $\mathrm{Cu}$ thickness from 20 to $40 \mathrm{~nm}$. AFM images are taken by scanning an area of $2 \times 2 \mu \mathrm{m}$.
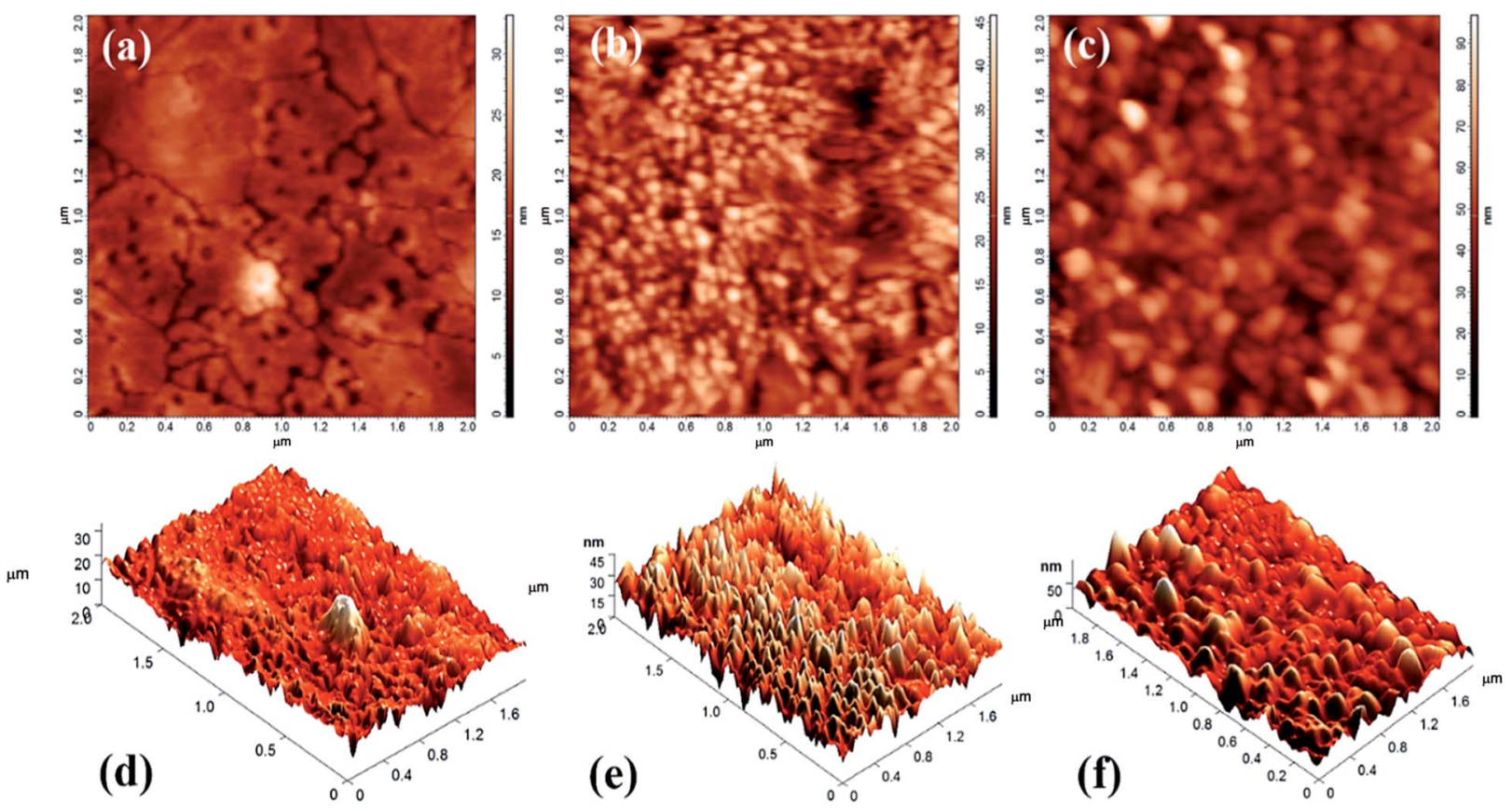

Fig. 5 Atomic force micrographs (2D) for $\mathrm{CuSbS}_{2}$ thin films with varying Cu thicknesses (a) CAS 20 (b) CAS 30 (c) CAS 40 and (d-f) their corresponding 3D images. 


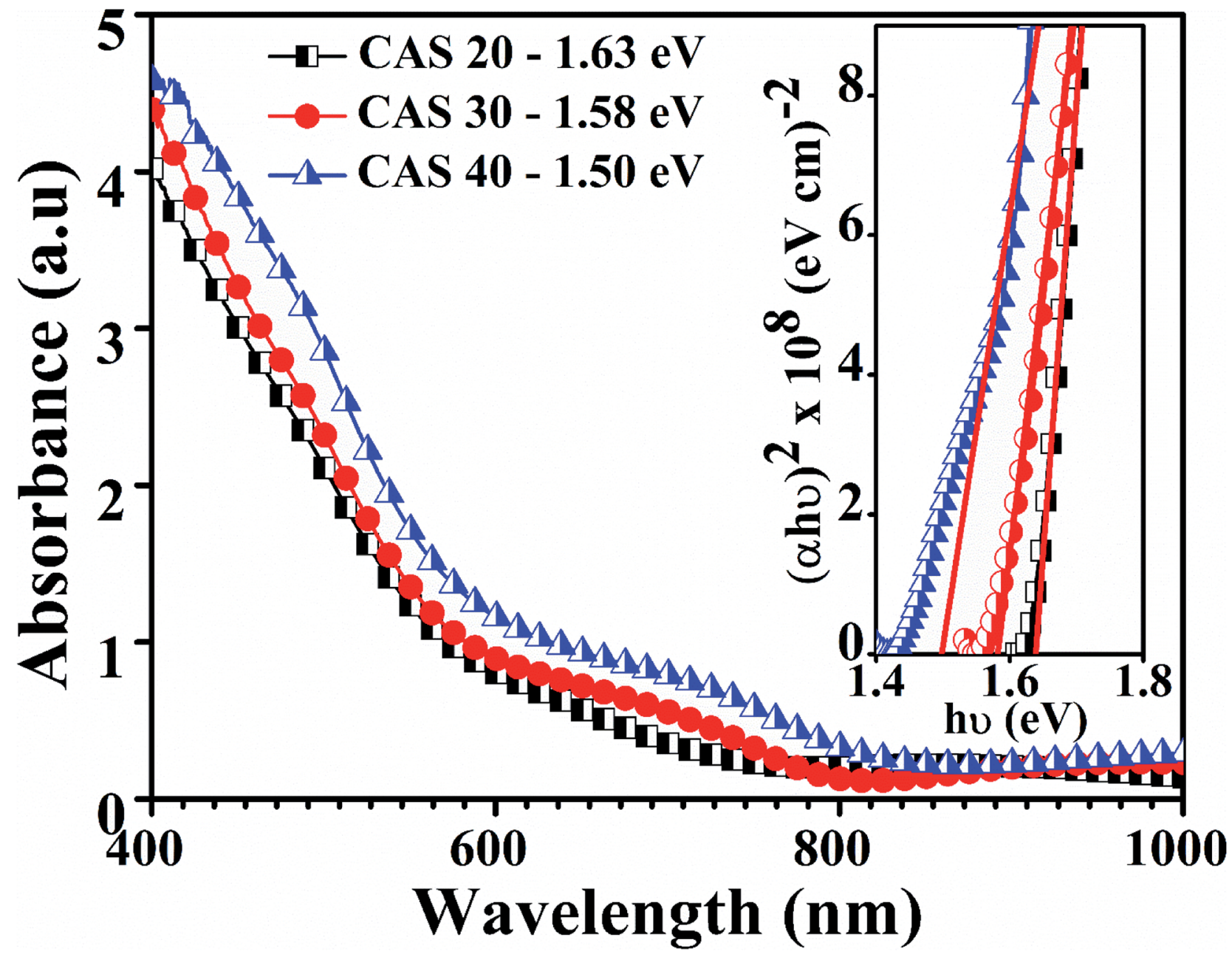

Fig. 6 Optical absorption spectra of phase pure CAS thin films with varying Cu thicknesses 20, 30, and $40 \mathrm{~nm}$. Tauc plots for the evaluation of optical bandgaps are given in the inset.

Roughness of the film surfaces calculated are $2.99 \mathrm{~nm}, 6.36 \mathrm{~nm}$ and $11.34 \mathrm{~nm}$ respectively for CAS 20,30 and 40 . Surface of the films appears as flat for the CAS 20 compared to other two whereas small grains appear in CAS 30 film. For CAS 40 much bigger spherical grains are identified. Change in morphology of the films with varying $\mathrm{Cu}$ thickness is evident from SEM and AFM images. In both cases CAS 40 film showed better surface morphology which is in good agreement with the XRD results having higher crystallinity.

\subsection{Optical properties}

The optical absorbance and energy bandgap of the CAS thin films deposited on glass substrates were evaluated using UVVis-NIR spectrometer for the range of 400-1000 nm. Fig. 6 shows the absorption spectra for CAS 20, 30 and 40 films and their bandgaps (inset) respectively. A broad as well as strong absorbance in the range of 400 to $800 \mathrm{~nm}$ and its reduction at higher wavelength is clear from the given spectra. Optical bandgap of the films calculated using the Tauc plots based on the relation,

$$
(\alpha h \nu)^{n}=A\left(h \nu-E_{\mathrm{g}}\right)
$$

where $\alpha$ is the absorption coefficient corresponding to the energy $h \nu$ where $h$ is the Plank's constant, $\nu$ is the frequency of the incident photon, and $A$ is a constant. The value of $n$ equals to 2 for an allowed direct, $1 / 2$ for an allowed indirect and 2/3 for a forbidden transition. Absorption coefficient $(\alpha)$ in the absorbance region was calculated using the eqn (3),

$$
\alpha=\frac{1}{d} \ln \frac{(1-R)^{2}}{T}
$$

where, $d$ is the thin film thickness $(\approx 220,230$ and 240 for CAS 20, 30 and 40 films), $R$ is the reflectance and $T$ is the transmittance (graphs of $T$ and $R$ is provided in the ESI, Fig. S6 $\dagger$ ). A good linear fit of $(\alpha h \nu)^{2} v s$. $h \nu$ (Tauc plot) is obtained for $n=2$ (direct-allowed transition) for all the CAS thin films which implies that in $\mathrm{CuSbS}_{2}$ films the fundamental optical absorption is dominated by direct allowed transition. ${ }^{11}$ The bandgap obtained for CAS 20, 30 and 40 films are 1.63, 1.58, $1.50 \mathrm{eV}$ respectively. ${ }^{43}$ The widest bandgap observed for $20 \mathrm{~nm}$ CAS film might be due to the higher extent of unreacted $\mathrm{Sb}_{2} \mathrm{~S}_{3}$ present in 

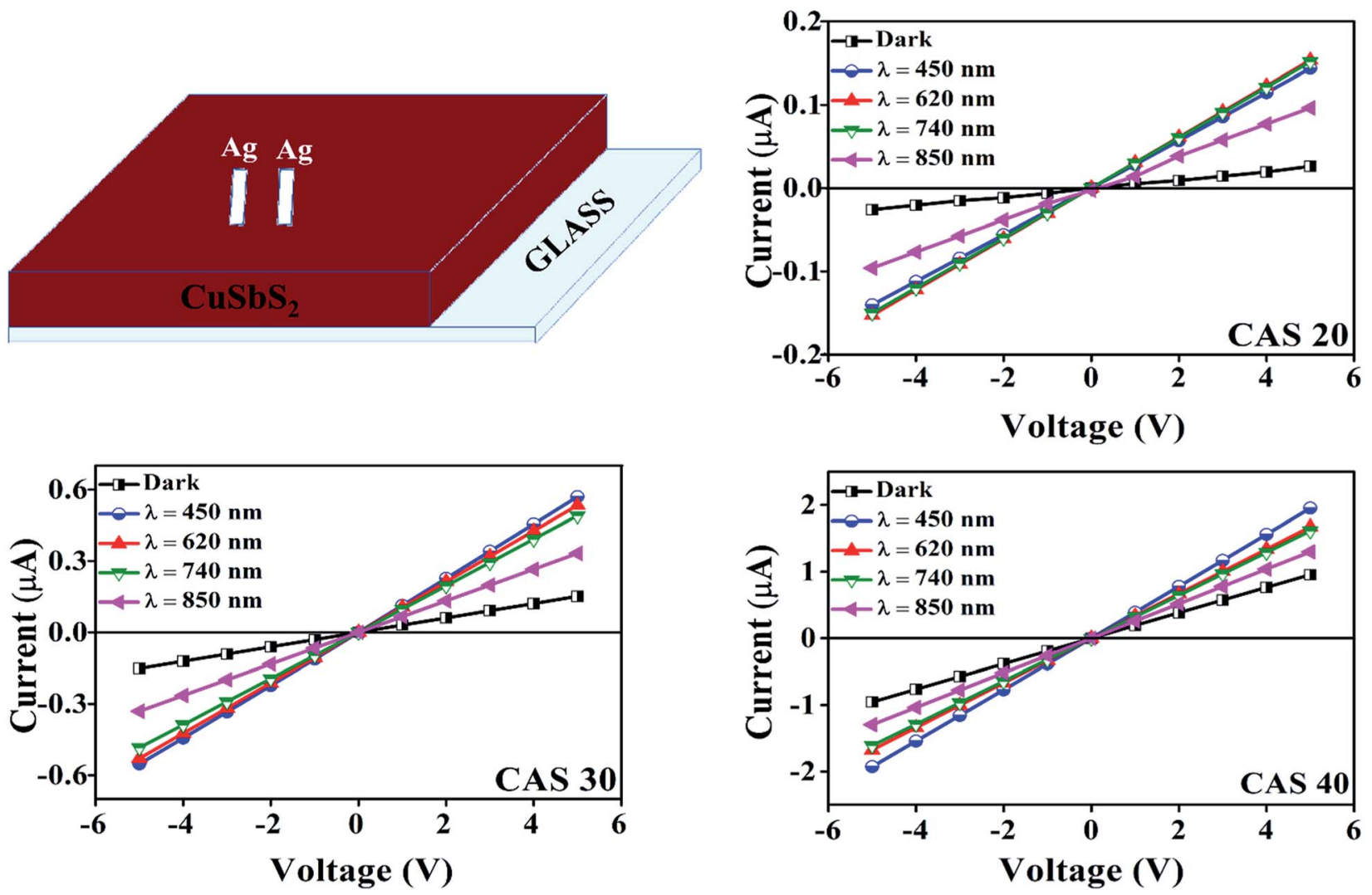

Fig. 7 Schematic representation of the CAS photodetector device, the current voltage curves of the CAS 20, 30 and 40 photodetectors under dark and illumination with different wavelength LED's (450, 620, 740 and $850 \mathrm{~nm}$ ) light.

it. Sanchez et al. reported that the higher electron-hole pair generation and potent absorption coefficient resulted due to the direct band gap ${ }^{44}$ which is suitable for the optoelectronic device applications. Furthermore, UV to NIR spectra detection would also be possible considering this direct band gap values. ${ }^{45}$

\subsection{Electrical and photodetector properties}

The current-voltage $(I-V)$ characteristics of $\mathrm{CuSbS}_{2}$ photodetector having varying $\mathrm{Cu}$ thicknesses under dark as well as illumination at different wavelength LEDs for an applied voltage from $-5 \mathrm{~V}$ to $+5 \mathrm{~V}$ is shown in Fig. 7. As shown in the figure, good symmetry and linear nature of the $I-V$ curves for all the films suggest better ohmic contact between the Ag electrodes and CAS films. The photocurrent analysis under dark as well as light at the same bias voltage shows a significant increase in current with the illumination. The p-type conductivity and high absorption coefficient favour this material for linear and symmetrical $I-V$ characteristics under dark and illuminated conditions. This linear and stable nature of $I-V$ characteristics under illumination agrees with the light absorption, charge carrier generation (electron-hole) and transport leading to increase in photocurrent compared to that in dark.

CAS 40 and CAS 30 showed the highest photocurrent for the illumination wavelength of $450 \mathrm{~nm}$ which coincide with the optical results where the maximum absorption was in this
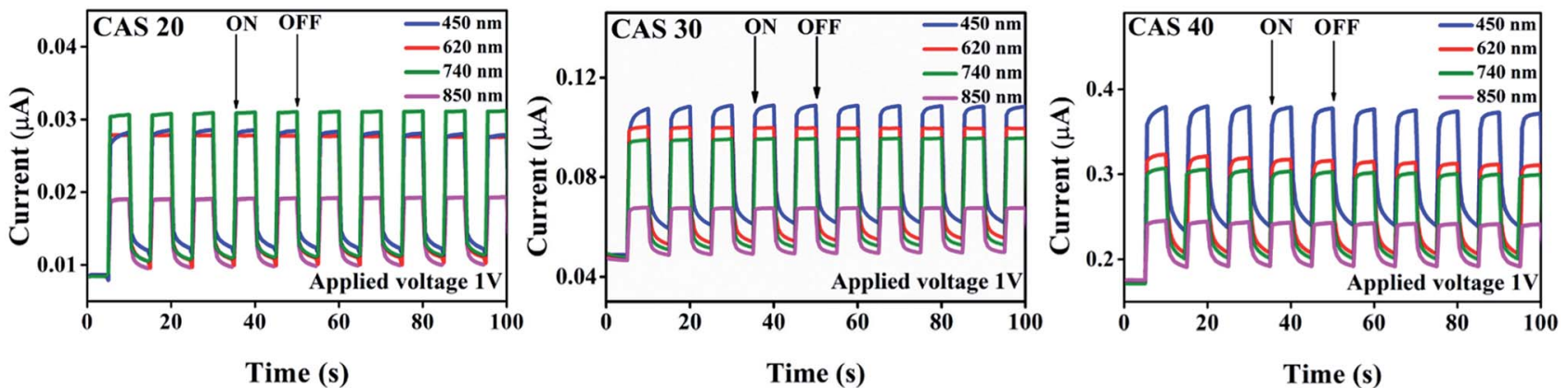

Fig. 8 Switching behaviour of CAS photodetector (CAS 20, CAS 30 and CAS 40) under illumination with LEDs having wavelengths $450,620,740$ and $850 \mathrm{~nm}$ for bias voltage $1 \mathrm{~V}$. 
wavelength range. These results are comparable with the performance of flexible photodetector based on SnS thin films by Mahdi et al. ${ }^{45}$ For the SnS photodetector illuminated by LED having wavelength of $380 \mathrm{~nm}$ showed better photocurrent rather than the LEDs with higher wavelengths which is well matching with the current work. Photoresponse of CAS 20, CAS 30 and CAS 40 samples at $1 \mathrm{~V}$ (photoresponse for applied voltages of 3 and $5 \mathrm{~V}$ are provided in ESI, Fig. S7 and S8 $\dagger$ ) under dark as well as illumination using LEDs having wavelength of $450,620,740$ and $850 \mathrm{~nm}$ at a cyclic interval of $5 \mathrm{~s}$ is shown in Fig. 8. As observed in the previous results, CAS 40 as well as 30 films show highest photocurrent for illumination having a wavelength of $450 \mathrm{~nm}$. CAS 20 shows better photocurrent for $740 \mathrm{~nm}$, which provides wavelength selective photodetection for CAS thin films. This might be due to the presence of binary impurity phases, defects present in this sample as well as the surface morphology. For all the samples, the photocurrent increased to a stable value under each bias voltage and reached back to its initial value as illumination is turned off (on/off nature of photocurrent), which shows the stability as well as reproducibility characteristics of the CAS photodetector. The cyclic photo response of the CAS films in the present work is of better stability with higher order of photocurrent $\left(10^{3}\right.$ times $)$ at much lower applied voltages compared to the results obtained for organic-inorganic photodetector based on $\mathrm{CuSbS}_{2}$ nanocrystals. ${ }^{6}$ The measure of change in conductivity of a sample upon illumination (photosensitivity) of the photodetectors are measured using eqn (4) ${ }^{\mathbf{4 5 , 4 6}}$ from both photoresponse using LEDs as well as the laser,

$$
S(\%)=\frac{\Delta I_{\lambda}}{I_{\mathrm{dark}}} \times 100
$$

The corresponding results are shown in Tables 1 and 2 for the applied bias voltage $1 \mathrm{~V}$ (sensitivity values corresponding to applied voltages $3 \mathrm{~V}$ and $5 \mathrm{~V}$ are provided in the ESI Tables ST1-ST4 $\dagger$ ). For the measurements using different wavelength LEDs, highest sensitivity for the CAS 20 sample is obtained for $740 \mathrm{~nm}$ whereas CAS 30 and CAS 40 samples show highest sensitivities for blue light $(450 \mathrm{~nm})$. The corresponding
Table 2 Sensitivity and responsivity measurements of CAS 20, CAS 30 and CAS 40 at various laser power density and applied voltage $1 \mathrm{~V}$

\begin{tabular}{|c|c|c|c|c|c|}
\hline Sample & $\begin{array}{l}\text { Power } \\
\text { density } \\
\left(\mathrm{mW} \mathrm{cm}{ }^{-2}\right)\end{array}$ & $\begin{array}{l}I_{\text {dark }} \\
(\mathrm{nA})\end{array}$ & $\begin{array}{l}I_{\text {light }} \\
(\mathrm{nA})\end{array}$ & $\begin{array}{l}\text { Sensitivity } \\
(\%)\end{array}$ & $\begin{array}{l}\text { Responsivity } \\
\left(\mathrm{A} \mathrm{W}^{-1}\right) \times 10^{-6}\end{array}$ \\
\hline \multirow[t]{6}{*}{ CAS 20} & 0.8 & 3.95 & 7.68 & 94.43 & 19.05 \\
\hline & 2.4 & 3.80 & 9.48 & 149.47 & 9.62 \\
\hline & 3.9 & 3.88 & 10.68 & 175.25 & 6.91 \\
\hline & 7.9 & 4.15 & 13.09 & 215.42 & 4.54 \\
\hline & 11.8 & 3.94 & 14.55 & 269.03 & 3.59 \\
\hline & 15.8 & 4.11 & 15.89 & 286.61 & 2.99 \\
\hline \multirow[t]{6}{*}{ CAS 30} & 0.8 & 71.4 & 72.3 & 1.26 & 4.57 \\
\hline & 2.4 & 71.7 & 76.9 & 7.25 & 8.81 \\
\hline & 3.9 & 71.6 & 80.3 & 12.15 & 8.84 \\
\hline & 7.9 & 74.8 & 88.1 & 17.78 & 6.76 \\
\hline & 11.8 & 74.9 & 92.7 & 23.76 & 6.03 \\
\hline & 15.8 & 76.6 & 95.8 & 25.06 & 4.88 \\
\hline \multirow[t]{6}{*}{ CAS 40} & 0.8 & 196 & 199 & 1.53 & 15.24 \\
\hline & 2.4 & 208 & 225 & 8.17 & 28.78 \\
\hline & 3.9 & 215 & 239 & 11.16 & 24.38 \\
\hline & 7.9 & 213 & 258 & 21.07 & 22.81 \\
\hline & 11.8 & 212 & 271 & 27.78 & 19.97 \\
\hline & 15.8 & 211 & 288 & 33.17 & 11.78 \\
\hline
\end{tabular}

photoresponse measurements using LEDs are shown in Fig. 8. Among all the samples, better sensitivity under all the wavelengths of illumination is recorded for CAS 20 film for all applied voltages. These results were further verified using another set of samples of CAS 20 thin films. From the analysis of structure and morphology of this sample, the presence of impurity phases as well as the different surface morphology of this sample might have contributed to this selective NIR photodetection with enhanced sensitivity.

Further, the response times (rise time and decay time) were also evaluated from the figure. The rise time of a photodetector is defined as the time needed to increase the photocurrent from $10 \%$ to $90 \%$ of its maximum value and the decay time as the time required for decreasing the photocurrent from $90 \%$ to $10 \% .{ }^{45}$ We calculated the rise and decay time of a single on/off at $1 \mathrm{~V}$ bias for samples CAS 20, CAS 30 and CAS 40 . The values are also included in Table 1.

Table 1 Sensitivity measurements of CAS 20, 30 and 40 using LEDs at applied voltage $1 \mathrm{~V}$

\begin{tabular}{|c|c|c|c|c|c|c|}
\hline Sample & Wavelength (nm) & $I_{\text {dark }}(\mathrm{nA})$ & $I_{\text {light }}(\mathrm{nA})$ & Sensitivity (\%) & Rise time (s) & Decay time (s) \\
\hline \multirow[t]{4}{*}{ CAS 20} & 450 & 8.52 & 27.65 & 224.47 & 0.51 & 3.1 \\
\hline & 620 & 8.53 & 27.86 & 226.56 & 0.42 & 2.8 \\
\hline & 740 & 8.47 & 30.53 & 260.62 & 0.46 & 2.5 \\
\hline & 850 & 8.51 & 18.90 & 122.14 & 0.53 & 3.0 \\
\hline \multirow[t]{4}{*}{ CAS30 } & 450 & 48.8 & 104.8 & 114.75 & 0.75 & 3.9 \\
\hline & 620 & 48.07 & 99.79 & 107.59 & 0.72 & 3.7 \\
\hline & 740 & 48.53 & 94.51 & 94.84 & 0.80 & 3.2 \\
\hline & 850 & 46.93 & 67.5 & 43.92 & 0.76 & 3.6 \\
\hline \multirow[t]{4}{*}{ CAS40 } & 450 & 173.05 & 372.39 & 115.03 & 1.7 & 3.8 \\
\hline & 620 & 172.82 & 321.08 & 85.55 & 1.4 & 3.4 \\
\hline & 740 & 171.18 & 304.61 & 78.12 & 1.3 & 3.3 \\
\hline & 850 & 175.29 & 243.87 & 39.42 & 1.2 & 3.4 \\
\hline
\end{tabular}



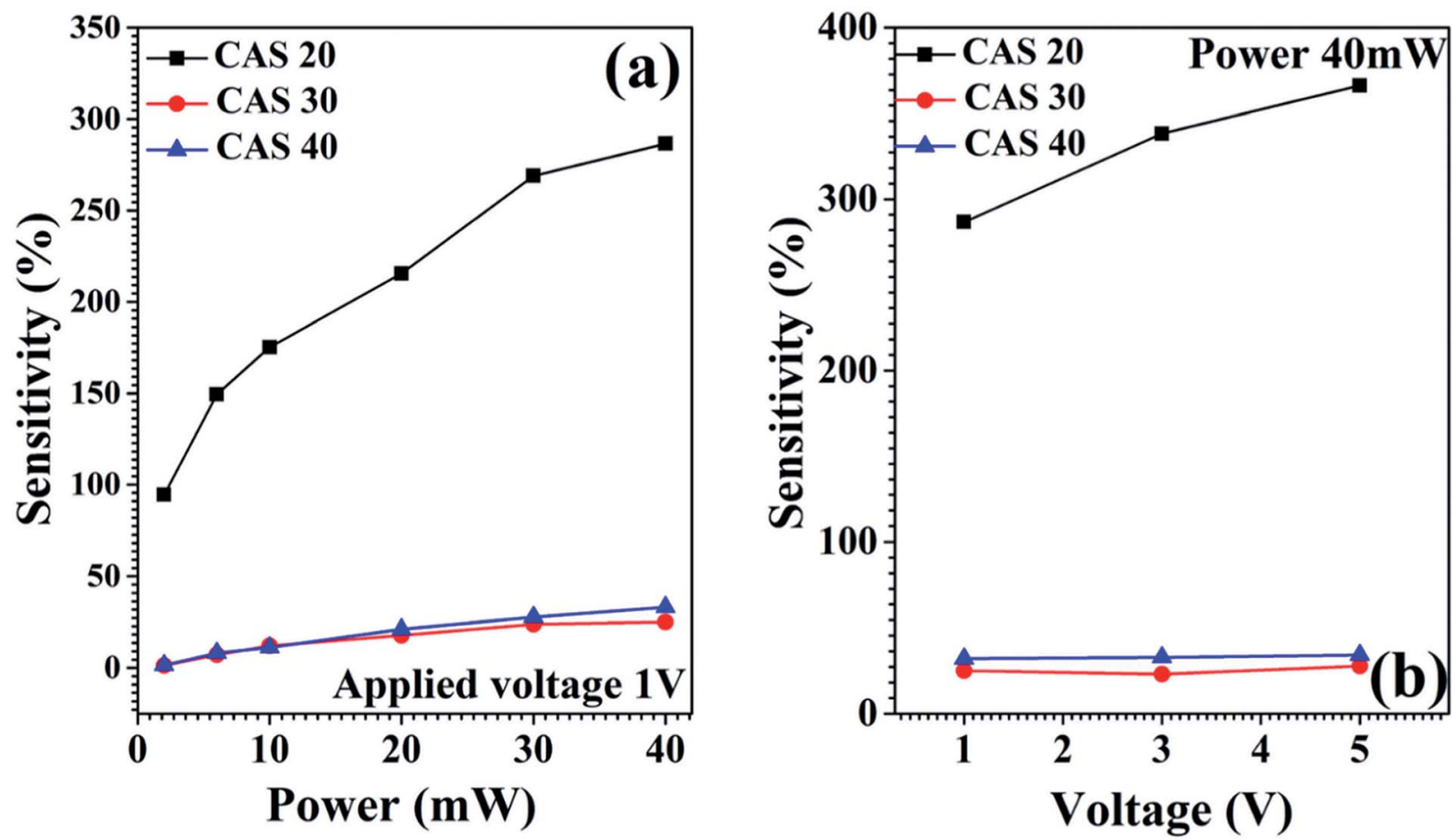

Fig. 9 (a) Laser power vs. sensitivity graphs of CAS 20, CAS 30 and CAS 40 samples at applied bias voltage 1 V. (b) Sensitivities of CAS 20 , CAS 30 and CAS 40 samples for varying bias voltages $(1,3$ and $5 \mathrm{~V})$ for the laser power $40 \mathrm{~mW}$.

Sensitivity measurements corresponding to the illumination by green laser $(532 \mathrm{~nm}$ ) for different laser power (applied voltage $1 \mathrm{~V})$ as well as for different applied bias voltages ( $1 \mathrm{~V}, 3 \mathrm{~V}$ and 5 V) are presented in Fig. 9 and the corresponding sensitivity values are shown in Table 2 . In accordance with the measurements using LEDs, highest sensitivities are recorded for the CAS 20 sample compared to CAS 30 and CAS 40, while illuminated using the laser. Sensitivity of all the three samples increases gradually with laser intensity. The amount of photocurrent generated per unit area per unit illumination intensity, responsivity $(R)$ is calculated for the structure glass $/ \mathrm{Sb}_{2} \mathrm{~S}_{3} / \mathrm{Cu} / \mathrm{Ag}$ for CAS 20, CAS 30 and CAS 40 from the cyclic photoresponse measurements (Fig. 8) using the following equation, ${ }^{46}$

$$
R=\frac{I_{\text {light }}-I_{\text {dark }}}{L_{\lambda} S}
$$

where $L_{\lambda}$ is the power density of the light source. Responsivity of the CAS detectors were calculated using eqn (5) from the measurements done by laser illumination at applied voltage $1 \mathrm{~V}$ and the corresponding values are included in Table 2. Highest responsivities were recorded for CAS 20 at the laser power of 2 $\mathrm{mW}$, CAS 30 at $10 \mathrm{~mW}$ and CAS 40 at $6 \mathrm{~mW}$ respectively. Sensitivity measurements of the samples at applied voltages $3 \mathrm{~V}$ and $5 \mathrm{~V}$ for varying laser power are included in the ESI (Tables ST2 and ST4 $\dagger$ ). Our experiments resulted improved photodetection characteristics compared to that of the hybrid photodetector based on $\mathrm{CuSbS}_{2}$ nanocrystals. ${ }^{6}$

The cyclic stability, linearity and ON/OFF photoresponse of the samples at low applied voltage are the merits of these CAS photodetectors. To check stability, the photoresponsivity of the
CAS photodetectors (CAS 20, CAS 30 and CAS 40) were measured under the same illumination conditions and bias voltage, after 5 months of their fabrication. The results are included in ESI (Fig. S10†). The device showed reliable photoconductive properties comparable with the newly fabricated device performance given in Fig. 8.

It is to be noted that in all the samples, the dark current is high due to high electrical conductivity of the samples. The conductivity of a material is an intrinsic property determined by the majority carrier concentration and their mobility. Our previous studies ${ }^{8}$ showed that CAS films produced by diffusing $\mathrm{Cu}$ into $\mathrm{Sb}_{2} \mathrm{~S}_{3}$ resulted high p-type conductivity due to high hole concentration in the range of $10^{18}$ to $10^{20} \mathrm{~cm}^{-3}$. Also, it is known that p-type conductivity is originated from $\mathrm{Cu}$ vacancies in $\mathrm{CuSbS}_{2}$ lattice. Thus, by fine control of $\mathrm{Cu} / \mathrm{Sb}$ ratio or adding suitable dopants to $\mathrm{CuSbS}_{2}$ without altering the phase purity, the dark conductivity may be modified.

Chalcogenide based binary, ternary and quaternary semiconductors and their composites have already proven to be apt candidates for photodetector applications owing to its unique semiconducting properties. For instance, inorganic thin film visible light photodetector based on graphene on antimony sulfide was reported by Xiao et $a l^{47}$ and stable photoresponse was obtained even at zero bias voltage for the wavelength range 400-700 nm. In addition, CuInS 2 thin film and CuInSe ${ }_{2}$ nanocrystals were also utilized for light detection applications by various research groups..$^{48,49} \mathrm{Hao}$ et al. reported the synthesis of a high-performance photodetector based on hybrid film of $\mathrm{CuSbS}_{2}$ nanocrystals and poly(3-hexylthiophene). ${ }^{6}$ Even though the constructed photodetector device had stable photodetection 
properties, better sensitivity was obtained in the infrared range. In the present work the synthesized CAS thin film photodetectors exhibit photodetection properties for different bias voltages, illumination wavelengths and intensities with excellent stability and reproducibility for the visible as well as NIR regions. The results of this study show that CAS photodetectors are promising optoelectronic devices at large area, low cost, environmentally benign and effective with wavelengthtailorability in visible to NIR backing low applied voltage operation.

\section{Conclusions}

In summary, we fabricated and characterized $\mathrm{CuSbS}_{2}$ thin films based photodetectors for three different $\mathrm{Cu}$ thicknesses $(20,30$ and $40 \mathrm{~nm}$ ). The structure, morphology and opto-electronic properties of the CAS films with special focus on the photodetection application were investigated in detail. Formation of $\mathrm{CuSbS}_{2}$ phase was confirmed by XRD, XPS and Raman analyses and their morphologies by SEM and AFM. Bigger grains were formed in the CAS 40 sample compared to the other two while the optical band gaps of the samples were in the range 1.50$1.63 \mathrm{eV}$. Photoresponse measurements of all the samples were recorded as a function of incident light wavelength using LEDs as well as function of incident light intensity using a laser. All the samples showed stable, reproducible photoconductive properties with high sensitivity and responsivity for low applied voltage. The present study can help in cost effective production of photodetector devices using environment friendly materials with selective wavelength detection properties at low cost in large area.

\section{Conflicts of interest}

There are no conflicts to declare.

\section{Acknowledgements}

V. Vinayakumar is thankful to Consejo Nacional de Ciencia y Tecnología (CONACYT-Mexico) for providing a doctoral fellowship. Financial support from CEMIE-Sol Project 35 (SENERCONACYT, Mexico) is gratefully acknowledged.

\section{References}

1 D. Aldakov, A. Lefrançois and P. Reiss, J. Mater. Chem. C, 2013, 1, 3756-3776.

2 M. G. Panthani, V. Akhavan, B. Goodfellow, J. P. Schmidtke, L. Dunn, A. Dodabalapur, P. F. Barbara and B. A. Korgel, J. Am. Chem. Soc., 2008, 130, 16770-16777.

3 J.-J. Wang, Y.-Q. Wang, F.-F. Cao, Y.-G. Guo and L.-J. Wan, J. Am. Chem. Soc., 2010, 132, 12218-12221.

4 E. Badradeen, M. Brozak, F. Keles, K. Al-Mayalee and T. Karabacak, J. Vac. Sci. Technol., A, 2017, 35, $03 \mathrm{E} 112$.

5 A. W. Welch, P. P. Zawadzki, S. Lany, C. A. Wolden and A. Zakutayev, Sol. Energy Mater. Sol. Cells, 2015, 132, 499-506.
6 M. Hao, Y. Liu, F. Zhou, L. Jiang, F. Liu and J. Li, ECS Solid State Lett., 2014, 3, Q41-Q43.

7 Y. Rodriguez-Lazcano, M. Nair and P. Nair, J. Cryst. Growth, 2001, 223, 399-406.

8 C. Garza, S. Shaji, A. Arato, E. P. Tijerina, G. A. Castillo, T. D. Roy and B. Krishnan, Sol. Energy Mater. Sol. Cells, 2011, 95, 2001-2005.

9 B. Yang, L. Wang, J. Han, Y. Zhou, H. Song, S. Chen, J. Zhong, L. Lv, D. Niu and J. Tang, Chem. Mater., 2014, 26, 3135-3143.

10 K. Ramasamy, H. Sims, W. H. Butler and A. Gupta, Chem. Mater., 2014, 26, 2891-2899.

11 R. Ornelas-Acosta, S. Shaji, D. Avellaneda, G. Castillo, T. D. Roy and B. Krishnan, Mater. Res. Bull., 2015, 61, 215225.

12 W. Septina, S. Ikeda, Y. Iga, T. Harada and M. Matsumura, Thin Solid Films, 2014, 550, 700-704.

13 L. Yu, R. S. Kokenyesi, D. A. Keszler and A. Zunger, Adv. Energy Mater., 2013, 3, 43-48.

14 E. Peccerillo, J. Major, L. Phillips, R. Treharne, T. J. Whittles, V. Dhanak, D. Halliday and K. Durose, IEEE 40th Photovoltaic Specialist Conference (PVSC), 2014, pp. 0266-0269.

15 S. C. Riha, A. A. Koegel, J. D. Emery, M. J. Pellin and A. B. Martinson, ACS Appl. Mater. Interfaces, 2017, 9, 46674673.

16 S. Banu, S. J. Ahn, S. K. Ahn, K. Yoon and A. Cho, Sol. Energy Mater. Sol. Cells, 2016, 151, 14-23.

17 A. W. Welch, L. L. Baranowski, P. Zawadzki, C. DeHart, S. Johnston, S. Lany, C. A. Wolden and A. Zakutayev, Prog. Photovoltaics, 2016, 24, 929-939.

18 F. W. de Souza Lucas, A. W. Welch, L. L. Baranowski, P. C. Dippo, H. Hempel, T. Unold, R. Eichberger, B. Blank, U. Rau and L. H. Mascaro, J. Phys. Chem. C, 2016, 120, 18377-18385.

19 W. Wubet and D.-H. Kuo, Mater. Res. Bull., 2014, 53, 290294.

20 C. Marino, T. Block, R. Pöttgen and C. Villevieille, J. Power Sources, 2017, 342, 616-622.

21 Z. Zhang, C. Zhou, Y. Liu, J. Li, Y. Lai and M. Jia, Int. J. Electrochem. Sci., 2013, 8, e10067.

22 Z. Zhang, Y. Fu, C. Zhou and Y. Lai, J. Electron. Mater., 2015, 44, 252-257.

23 M. Nair, Y. Pena, J. Campos, V. Garcia and P. Nair, J. Electrochem. Soc., 1998, 145, 2113-2120.

24 I. Popovici and A. Duta, Int. J. Photoenergy, 2012, 2012, 962649.

25 A. Rastogi and N. Janardhana, Thin Solid Films, 2014, 565, 285-292.

26 A. Rabhi, M. Kanzari and B. Rezig, Thin Solid Films, 2009, 517, 2477-2480.

27 R. Mane and C. Lokhande, Mater. Chem. Phys., 2000, 65, 131.

28 P. Nair, M. Nair, V. Garcıa, O. Arenas, Y. Pena, A. Castillo, I. Ayala, O. Gomezdaza, A. Sanchez and J. Campos, Sol. Energy Mater. Sol. Cells, 1998, 52, 313-344.

29 V. Vinayakumar, S. Shaji, D. Avellaneda, T. D. Roy, G. Castillo, J. Martinez and B. Krishnan, Sol. Energy Mater. Sol. Cells, 2017, 164, 19-27. 
30 B. Krishnan, A. Arato, E. Cardenas, T. D. Roy and G. Castillo, Appl. Surf. Sci., 2008, 254, 3200-3206.

31 Y. Rodríguez Lazcano, L. Guerrero, O. Gomez Daza, M. Nair and P. Nair, Superficies y vacio, 1999.

32 C. Macías, S. Lugo, Á. Benítez, I. López, B. Kharissov, A. Vázquez and Y. Peña, Mater. Res. Bull., 2017, 87, 161-166.

33 J. A. Ramos Aquino, D. L. Rodriguez Vela, S. Shaji, D. A. Avellaneda and B. Krishnan, Phys. Status Solidi C, 2016, 13, 24-29.

34 D. Colombara, L. M. Peter, K. D. Rogers, J. D. Painter and S. Roncallo, Thin Solid Films, 2011, 519, 7438-7443.

35 A. Bushroa, R. Rahbari, H. Masjuki and M. Muhamad, Vacuum, 2012, 86, 1107-1112.

36 J. Baker, R. S. Kumar, D. Sneed, A. Connolly, Y. Zhang, N. Velisavljevic, J. Paladugu, M. Pravica, C. Chen and A. Cornelius, J. Alloys Compd., 2015, 643, 186-194.

37 C. L. McCarthy, P. Cottingham, K. Abuyen, E. C. Schueller, S. P. Culver and R. L. Brutchey, J. Mater. Chem. C, 2016, 4, 6230-6233.

38 S. Thiruvenkadam and A. L. Rajesh, International Journal of Scientific \& Technology Research, 2014, 3, 38-41.

39 H. Guo, Y. Cui, Q. Tian, S. Gao, G. Wang and D. Pan, Cryst. Growth Des., 2015, 15, 771-777.
40 I. Efthimiopoulos, C. Buchan and Y. Wang, Sci. Rep., 2016, 6, 24246.

41 B. Minceva-Sukarova, M. Najdoski, I. Grozdanov and C. Chunnilall, J. Mol. Struct., 1997, 410, 267-270.

42 (http://rruff.info).

43 T. J. Whittles, T. D. Veal, C. N. Savory, A. W. Welch, F. W. de Souza Lucas, J. T. Gibbon, M. Birkett, R. J. Potter, D. O. Scanlon and A. Zakutayev, ACS Appl. Mater. Interfaces, 2017, 9, 41916-41926.

44 O. Lopez-Sanchez, D. Lembke, M. Kayci, A. Radenovic and A. Kis, Nat. Nanotechnol., 2013, 8, 497.

45 M. S. Mahdi, K. Ibrahim, A. Hmood, N. M. Ahmed, S. A. Azzez and F. I. Mustafa, RSC Adv., 2016, 6, 114980114988.

46 T. S. Reddy and M. S. Kumar, RSC Adv., 2016, 6, 9568095692.

47 Y. Xiao, C. Li, X. Tan, L. Zhang, Y. Zhong and H. Zhu, Sol. $R R L, 2017,1,1770146$.

48 S. Bulyarsky, L. Vostretsova and S. Gavrilov, Semiconductors, 2016, 50, 106-111.

49 R. Guo, T. Shen and J. Tian, J. Mater. Chem. C, 2018, 6, 25732579. 